\title{
Ambrosya Böcekleri (Coleoptera: Curculionidae: Scolytinae ve Platypodinae) ile Ambrosya Fungusları Arasındaki Simbiyotik iliş̧kiler
}

\author{
Rahman KUSHIYEV ${ }^{1}$, Onur AKER ${ }^{1 *}$, Celal TUNCER ${ }^{1}$ \\ ${ }^{1}$ Ondokuz Mayıs Üniversitesi, Ziraat Fakültesi, Bitki Koruma Bölümü, Atakum, Samsun \\ *Sorumlu yazar: onur.aker@omu.edu.tr
}

Öz

Ambrosya böceklerinin her birinin bir veya birkaç simbiyotik fungusla ilişkili olduğu bilinmektedir. Simbiyotik funguslar bu böceklerin ergin ve larvalarının ana besin kaynağını oluşturmaktadır. Ambrosya böceklerinin erginleri ağaçların odun dokusunda açtıkları galerilerine, fungus keselerinde (Mycangia) taşıdıkları simbiyotik fungusları bulaştırarak yetiştirmektedir. Fakat mycocleptic türler olarak bilinen bazı küçük ambrosya böceği türlerinin ise fungus keseleri bulunmadığından simbiyotik fungusları taşımamaktadır. Ambrosya böcekleri orman ve meyve ağaçlarında önemli kayıplara neden olmaktadır. Bununla birlikte, ambrosia funguslarının da ağaçların çürümesinde önemli rol oynadığı bilinmektedir. Bu fungusların gelişimlerini kontrol altına alabilecek etkili bir yöntem bulunduğu takdirde, ambrosya böcekleri ile mücadelede alternatif yöntemler geliştirilebilecektir.

Anahtar Kelimeler: Ambrosya böcekleri, Ambrosya fungusları, Simbiyotik ilişki

\section{The Symbiotic Relationships Between Ambrosia Beetles (Coleoptera: Curculionidae: Scolytinae and Platypodinae) and Ambrosia Fungi}

\begin{abstract}
It is known that each of the ambrosia beetles is associated with one or more symbiotic fungi. The symbiotic fungi are the major food sources of adult and larvae of ambrosia bettles. Ambrosia beetles excavate tunnels in the wood tissue of trees in which they inoculate and cultivate symbiotic fungi which carry in their fungi pouch (Mycangia). Fungi pouch of some little ambrosia beetles were lost and they can not carry symbiotic fungi in their bodies and are known as mycocleptic. Ambrosia beetles cause significant loss in forests and fruit trees. However, it is known that ambrosia fungi also play an important role in the decay of trees. If there is find out an effective method to under control the development of these fungi, alternative methods of combating with ambrosia beetles will be developed.
\end{abstract}

Key Words: Ambrosia beetles, Ambrosia fungi, Symbiotic relationship

\section{Giriş}

Tanımında bazı farklılıklar bulunmakla beraber, simbiyotizm birarada bulunan canlıların karşılıklı yarar sağlamasına dayanan bir ilişki modeli olup, çok sayıda canlı türünde görülmektedir (Douglas, 2010). Simbiyotik yaşayan canlılar birlikte evrimleşmiş olup, hayatlarının devamı için birbirlerine intiyaç duymaktadırlar (Beaver, 1989). Böcek ve fungus türleri arasında görülen simbiyotik ilişkiler de bunlardan birisidir. Funguslar ile simbiyotik ilişki birçok böcek grubunda görülmekle birlikte; karıncalar (Hym.: Formicidae, Myrmicinae, Attini), termitler (Isop.: Termitidae, 
Macrotermitinae) ve ambrosya böceklerinde (Col.: Curculionidae, Scolytinae ve Platypodinae) bu ilişki ileri derecede evrimleşmiştir (Mueller ve ark., 2005). Karıncaların, başta Myrmicinae altfamilyası olmak üzere funguslarla simbiyotik iliş̧i içerisinde olan yaklaşık 220 türü tanımlanmıştır (Schultz ve Meier, 1995; Price ve ark. 2003). Termitlerin ise Macrotermitinae altfamilyasındaki yaklaşık 330 türü, Termitomyces cinsine giren funguslar ile simbiyotik ilişki oluşturmaktadır. Funguslarla simbiyotik ilişki içerisinde olan termit ve karıncalar bilimsel açıdan yeterince araştırılmış olmasına rağmen, ambrosya böceklerinin sadece belirli bir kısmı üzerinde çalışılımıştır.

Scolytinae altfamilyası, kabukta üreyen kabuk böcekleri ve odunda üreyen kabuk böcekleri (ambrosya böcekleri) olmak üzere başlıca iki grupta incelenmektedir (Selmi, 1998). Kabukta üreyen kabuk böcekleri phloeophagous özelliktedir, yani onlar doğrudan ölü bitki dokuları ve çoğu zaman da besince zengin floem ile kabuk içinde beslenirler. Ambrosya böcekleri hemen her zaman galerilerini ölü veya ölmek üzere olan bitkilerin özsuyu akışı yüksek odun dokusu içinde açarak simbiyotik fungusu bulaştırır ve üzerinde beslenirler. Ambrosya böceklerinin çoğu mycetophag ve xylomycetophag olarak beslenirler. Mycetophages olanlarda, larva ve erginler sadece simbiyotik ilişkili oldukları funguslar üzerinde beslenirken, xylomycetophages olanlar fungus ile beraber ksilem dokusunun parçalarını da sindirirler (Roeper, 1995). Böylece hem ambrosya böceklerinin hem de ambrosya funguslarının nesli bu simbiyotik ilişki sayesinde devam edebilmektedir (Harrington, 2005).

Ambrosya böcekleri ve ambrosya fungusları, eukaryotik canlılar arasında simbiyotik ilişkiye sahip en başarıı gruplardan birisidir (Vega ve Blackwell, 2005; Hulcr ve ark., 2007) ve aynı zamanda orman ekosisteminde de en yaygın görülen simbiyotik ilişkili gruplardan birisini oluşturmaktadırlar (Kostovcik ve ark., 2015). Ambrosya böcekleri ve ambrosya fungusları arasındaki ilişkilerin detaylı olarak ortaya konması, bu zararlı böcekler ile mücadelede farklı yaklaşımların ortaya çıkmasına yardımcı olacaktır. Örneğin ambrosya funguslarının gelişimini önleyecek bir yaklaşım, yaşamak için bu funguslara mutlak bağımlı olan ambrosya böceklerinin mücadelesini de sağlamış olacaktır.

\section{Ambrosya Böcekleri}

Ambrosya böcekleri, Scolytinae ve Platypodinae altfamilyalarında bulunan türlerin yaklaşık 3400'ünü içine alan bir gruptur (Farrell ve ark., 2001). Bu türler genellikle Scolytinae altfamilyasında bulunan Xyleborini ve Corthylini tribülerinde toplanmıs olup, Xyleborini tribüsü yaklaşık 1300 ambrosya böceği türünü içine almaktadır. Ayrıca Xyleborini tribüsünde bulunan ambrosya böcekleri hızlı çoğalan, hızlı yayılan, ekolojik ve ekonomik bakımdan en önemli grup olarak bilinmektedir (Farrell ve ark., 2001). Platypodinae altfamilyası ise yaklaşık 1500 ambrosya böceği türünü içine almaktadır (Wood ve Bright, 1992; Beaver ve Liu 2013). Bu alt familyalara ait geri kalan türlerin çoğunu ise genellikle ağaçların kabuk dokusu altında (floem) beslenen türler oluşturmaktadır. Kabuk böceklerinin sıklıkla Ascomycota ve Basidiomycota fungus türleri ile ilişkili olduğu, ancak böcek-fungus arasında zorunlu bir ilişkinin olmadığı belirtilmiştir (Harrington, 2005; Vega ve Hofstetter, 2015).

Ambrosya böcek türlerinin çoğunda, karınca ve arılarda olduğu gibi sosyal yaşam görülmektedir. Erkekler genellikle kısa 
ömürlü ve uçma kabiliyetini kaybetmiş olup, sadece dişiyi dölleme görevini yapmaktadır (Norris, 1979; Biedermann ve Taborsky, 2011). Bu nedenle, galerilerin açılması ve simbiyotik fungusların yetiştirilmesi gibi görevlerden dişi bireyler sorumlu olmaktadır.

Ambrosya böcekleri, genellikle stresli ve zayıf ağaçları tercih eden sekonder türler olarak bilinmelerine rağmen, bazı türlerin sağlıklı ağaçlara da saldırdığı bilinmektedir (Farrell ve ark., 2001). Ambrosya böcekleri orman ve meyve ağaçlarının önemli zararlılarından olup, bazı türleri zarar sonucu ağaçların ölümüne neden olmakta (Hudson ve Mizell, 1999; Oliver ve Mannion, 2001; Kuhnholz ve ark., 2003) ve her geçen gün yeni coğrafik bölgelere yayılmaktadırlar (Hulcr ve Dunn, 2011). Bu grubun ülkemizde de orman ve meyve ağaçlarında zararlı birçok türü bulunmaktadır (Selmi, 1998; Saruhan ve Tuncer, 2001; Cebeci ve Ayberk, 2010).

\section{Ambrosya Fungusları ve Simbiyotik ilişkileri}

Ambrosya fungus türlerinin monofiletik bir grubu ifade etmediği, bu fungusların ambrosya böcekleri tarafından türe spesifik olarak taşındığı düşünülmektedir (Mueller ve ark., 2005). Bu fungus türlerinin yalnızca küçük bir kısmı tanımlanmış olup, bu türlerin de primer veya sekonder simbiyotik funguslar olup olmadıkları tam olarak bilinmemektedir. Ancak, ambrosya böceklerinin her birinin bir veya birkaç simbiyotik fungusla ilişkili olduğu bilinmektedir (Batra, 1963; Funk, 1970). Ambrosya böceklerinin genellikle Ambrosiella ve Raffaelea cinsi (Ascomycota) funguslarla simbiyotik ilişkili olduğu görülmüştür (Harrington, 2009). Ayrıca, Ophiostoma, Leptographium, Fusarium, Dryadomyces cinslerine ait birçok fungus türü de bazı ambrosya böcek türleri ile ilişkili bulunmuştur (Kok, 1979; Norris, 1979;
Beaver, 1989; Gebhardt ve ark., 2004; Kirisits, 2004). Bazı ambrosya fungusları tek bir böcek türü ile ilişkiliyken, bazıları ise birden fazla böcek türü ile ilişkili olabilmektedir. Örneğin; Ambrosiella xylebori Brader ex Arx \& Hennebert (Microascales: Ceratocystidaceae) fungusu Xylosandrus compactus Eichhoff (Col.: Curculionidae: Scolytinae)' un yanı sıra, Corthylus columbianus Hopkins (Col.: Curculionidae: Scolytinae) ve Corthylus punctatissimus Zimmermann (Col.: Curculionidae: Scolytinae) türleri ile ilişkili olarak belirlenmiştir (Batra, 1967; Roeper, 1995). Ayrica, Anisandrus dispar Fabricius (Col.: Curculionidae: Scolytinae) ile ilişkili olduğu bilinen Ambrosiella hartigii (Microascales: Ceratocystidaceae) fungusunun Xylosandrus germanus Blandford (Col.: Curculionidae: Scolytinae), Anisandrus sayi Hopkins (Col.: Curculionidae: Scolytinae) ve Anisandrus obesus LeConte (Col.: Curculionidae: Scolytinae) türleri ile de ilişkili olduğu belirlenmiştir (Roeper, 1995).

Ambrosya böcekleri ile doğrudan ilişkili primer fungusların yanı sıra, daha zayıf ilişkili ve özel olarak taşınmayan sekonder fungus türlerinin de bulunduğu bilinmektedir (Kok ve ark., 1970; Beaver, 1989). Ancak, ambrosya böcekleri fungus keselerinde genellikle yalnızca primer simbiyotik fungusları taşımakta (bazen keselerden sekonder fungusların izole edilmesine rağmen) ve galerilerinde bu primer fungusları yetiştirmektedir (FranckeGrosmann, 1967; Norris, 1979; Gebhardt ve ark., 2004). Örneğin; yapılan bir çalışmada Xyleborinus saxesenii Ratzeburg (Col.: Curculionidae: Scolytinae)' nin primer olarak Raffaelea sulphurea (Batra) T.C. Harr. (Ophiostomatales: Ophiostomataceae) ve sekonder olarak Fusicolla acetilerea (Tubaki, C. Booth \& T. Harada) Gräfenhan \& Seifert 
(Hypocreales: Nectriaceae) fungus türleri ile ilişkili olduğu belirlenmiştir. Ayrıca Xyleborini türleri ile ilişkili primer simbiyotik fungus türlerinin aseksüel olduğu (Rollins ve ark., 2001), sekonder fungus türlerinin ise genel olarak seksüel olduğu belirtilmiştir (FranckeGrosmann, 1967).

Ambrosya böceklerinin dişileri ağaçların odun dokusunda simbiyotik fungusların gelişebilmesi için galeriler açmakta ve fungus keselerinde taşıdıkları simbiyotik fungusları galerilerin duvarlarına bulaştırmmaktadır (Beaver, 1989; Mueller ve ark., 2005). Böcek tarafından aşılanan ambrosya fungusları, birkaç gün içerisinde gelişme göstermekte (Francke-Grosmann, 1967) ve fungusların gelişim göstermeye başladıkları andan itibaren dişi böcekler yumurtalarını galeri içlerine bırakmaya başlamaktadır (French ve Roeper, 1972; Roeper ve ark., 1980; Beaver, 1989) (Şekil 1). Dişi böcekler, yumurtalarını veya pupalarını fazla gelişen ambrosya funguslarından ve galeriye bulaşabilecek diğer patojenlerden korumak amacıyla galerin içerisinde sürekli temizlik ve bakım yapmaktadırlar (FranckeGrosmann, 1967; Biedermann ve Taborsky, 2011). Bazı çalışmalarda dişi ambrosya böceklerinin galerilerin içerisinde öldüğü durumlarda, galerilerde hızla patojen fungus ve bakterilerin geliştiği gözlemlenmiştir (Norris, 1979).

Simbiyotik funguslar ergin ve larvaların beslenmesi için bol miktarda misel oluşturmakta ve bu durum yalnızca ambrosya böceklerinin varlığında meydana gelmektedir (French ve Roeper, 1972). Bazı türler hariç, ergin ve larvaların ikisi de sadece simbiyotik funguslar üzerinde beslenmektedir. Ambrosya fungusları, ambrosya böceklerinin beslenebilmesi için ksilem ve diğer çevre dokulardan besin oluşturmakta, aminoasitler, vitaminler ve steroidler gibi organik moleküller sağlamaktadırlar (Kok, 1979; Norris, 1979; Beaver, 1989). Bazı sekonder fungus türlerinin de böceklerin beslenmesi ve gelişmesinde rol oynadığı, ancak böceğin hayatta kalması için tek başına yeterli olmadığı görülmektedir (Norris, 1979).

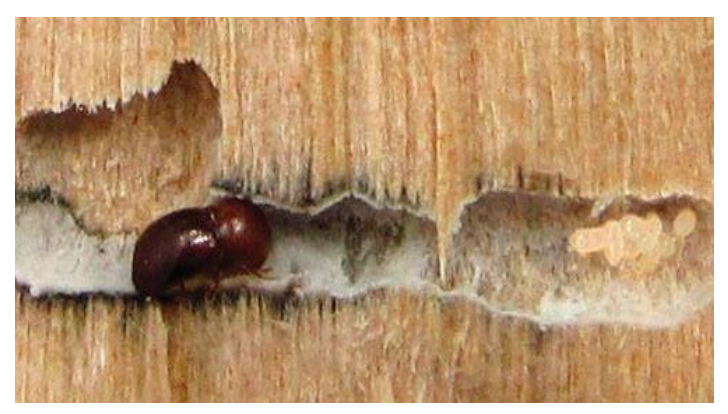

Şekil 1. Xylosandrus crassiusculus Motschulsky (Col.: Curculionidae: Scolytinae)' un galerilerinde yetiştirdiği fungus (Ambrosiella xylebori) ve galerilere yerleştirdiği yumurtalar (Hulcr ve Dunn, 2011).

Figure 1. Fungi (Ambrosiella xylebori) that were cultivated by Xylosandrus crassiusculus Motschulsky (Col.: Curculionidae: Scolytinae) in the galleries and the eggs are settled to the galleries.

Ambrosya böcekleri ve fungusları arasındaki ilişkinin mekanizması tam olarak anlaşılamamıştır. Pupa evresini tamamlayarak ergin döneme geçen ve henüz galeriyi terk etmemiş olan yeni erginlerin ambrosya fungusları üzerinde beslenmesinin, fungus keseleri içerisine ambrosya funguslarını alabilmesi için önemli olduğu belirtilmiştir (Kirkendall ve ark., 2015). Ambrosya böcekleri ile simbiyotik ilişki içinde olduğu bilinen Ambrosiella türlerinin tümünün bir koku ürettiği (Harrington, 2009) ve bu kokuların galerideki yeni erginleri çektiği belirlenmiştir (Hulcr ve ark., 2011). Aynı zamanda galeri içerisinde bulunan 
patojen fungusların ise böcekler üzerine repellent etkisinin olduğu bildirilmiştir (Hulcr ve ark., 2011). Bunun yanında bazı ambrosya fungus türlerinin söz konusu böcekler ile taşınmasını kolaylaştıracak şekilde yapışkan sporlar ürettikleri görülmüşür (Hsiau ve Harrington, 2003).

\section{Ambrosya Fungus Keseleri (Mycangia)}

Ambrosya böcekleri evrimsel süreç içerisinde, simbiyotik fungusları bir bitkiden diğerine taşımak amacıyla vücutlarının değişik yerlerinde türe özgü farklılıklar gösteren yapılar geliştirmişlerdir. Mycangia adı verilen bu özel fungus keseleri ambrosya böceklerinin sadece erginlerinde bulunmaktadır (Batra, 1963, 1967; Beaver, 1989; Harrington ve ark., 2014). Fungus kesesi; çevresi salgı bezleri ile çevrili, türden türe değişiklik gösteren, bazı türlerde basit ve bazılarında ise oldukça gelişmiş yapılar olarak ilk defa Batra (1963) tarafından tanımlanmıştır. Fungus kesesinde bulunan salgı bezlerinin simbiyotik fungusların canlılı̆ının korunmasında yardımcı olduğu bilinmektedir (Norris, 1979). Fungus kesesinin yeri ve morfolojik yapısı türden türe değişmekle birlikte, özellikle mandibula, elytra, mesotoraks ve metatoraks gibi değişik vücut kısımlarında bulunmaktadır (Batra, 1963; Hulcr ve ark., 2010).

Platypodinae altfamilyasında bulunan türler oldukça küçük ve basit fungus keselerine sahipken (Marvaldi ve ark., 2002), Xyleborini tribüsü içindeki Xylosandrus, Anisandrus ve Cnestus türleri mesonotum kısmında bulunan büyük ve gelişmiş fungus keselerine sahiptir (Francke-Grosmann, 1956, 1967; Beaver, 1989; Hulcr ve ark., 2007; Hulcr ve Cognato, 2010). Bunun dışında, Xyloterini tribüsünde bulunan Trypodendron spp.'nin dişileri büyük, boru şeklinde (pleuralprothoracic) bir fungus kesesine sahiptir (Francke-Grosmann, 1956, 1967). Ancak, bazı türlerde fungus keseleri böceklerin sadece vücutlarının değişik kısımlarında bulunan basit yapılar şeklindedir. Ayrıca, mycocleptic olarak bilinen bazı küçük ambrosya böcek türlerinin ise fungus keseleri kaybolmuştur (Hulcr ve Cognato, 2010).

Fungus Hirsızı (Mycocleptic) Ambrosya Böcekleri

Ambrosya böceklerine ait bazı küçük türlerin vücutlarında fungus keselerinin bulunmadığı belirlenmiştir. Bu türler, fungus kesesi taşıyan ambrosya böcekleri tarafından açılan büyük galerilerin yakınında veya bitişiğinde küçük galeriler açmakta, daha sonra büyük galerilerde gelişen simbiyotik fungusların kendi galerilerine yönlenmesini sağlamaktadırlar. Fungus kesesi taşımak yerine, diğer ambrosya böceklerinin galerilerinden fungus hırsızlığı yapılarak gerçekleştirilen fungus yetiştirme durumuna "mycocleptism" adı verilmiştir. Fungus hırsızlığı yapan bu türler ise "mycocleptic" türler olarak adlandırılmıştır (Hulcr ve Cognato, 2010) (Şekil 2).

Yapılan çalışmaların neticesinde, 15 Paleotropikal ve 1 Neotropikal olmak üzere toplamda 5 farklı cinse ait 16 mycocleptic ambrosya böcek türü belirlenmiştir. Fungus hırsızlığı yapmayan az 10 farklı cinse ait toplam 19 ambrosya böcek türünün ise mycocleptic türler tarafından mağdur edildiği belirlenmiştir. Mycocleptic türlerden bazılarının, mağdur pozisyonundaki türlere karşı önemli derecede spesifiklik gösterdiği bilinmektedir. Örneğin; Ambrosiophilus cinsine ait birçok mycocleptic türün genel olarak Beaverium cinsine ait ambrosya böcek türleri ile ilişki içinde olduğu gözlemlenmiştir (Hulcr ve Cognato, 2010). 


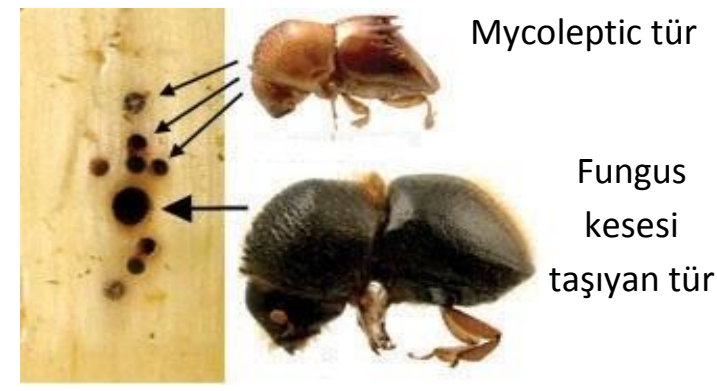

Şekil 2. Fungus hırsızlığı (Hulcr ve Cognato, 2010)

Figure 2. Mycocleptism

\section{Sonuçlar}

Ambrosya böcekleri dünyanın birçok bölgesinde bulunmakta olup, özellikle orman ve meyve ağaçlarında önemli kayıplara neden olmaktadırlar (Hulcr ve Dunn, 2011). Bir ağaçta, ambrosya böceklerinin yüzlercesi bulunabilmekte ve zamanla çevredeki diğer ağaçlarada yayılarak bu ağaçların kurumasına neden olabilmektedirler. Ayrıca, ambrosya böceklerinin kendi zararlarının yanında simbiyotik ilişkili olduğu ambrosya funguslarınında ağaçların besin ve su akışını bozarak bu ağaçların büyümesini etkilediği ve hatta bazı fungus türlerinin ağaçların kurumasında önemli rol oynayan bitki patojeni türler olduğu bilinmektedir (Castrillo ve ark., 2011).

Ambrosya böcek türlerinin ağaçların odun dokusu içerisindeki galerilerde bulunması ve ergin çıkış zamanlarının geniş aralıklara yayılması gibi nedenlerden dolayı bu zararlı türler ile mücadele yöntemleri yetersiz kalmaktadır (Saruhan ve Akyol, 2012). Son zamanlarda bu türlere karşı alternatif mücadele yöntemi olarak farklı bazı tuzaklar geliştirilmiş, ancak istenilen düzeyde başarı elde edilememiştir. Bu nedenlerden dolayı, bu türlere karşı farklı mücadele yöntemlerinin geliştirilmesine ihtiyaç duyulmaktadır (Hain, 2006). Ambrosya böceklerinin birlikte yaşadıkları ve birbirlerine mutlak ihtiyaç duydukları ambrosya fungusların bilinmesi bu bakımdan büyük önem taşımaktadır (Mayers ve ark., 2015). Bu fungusların gelişimlerini kontrol altına alabilecek etkili bir yöntem bulunduğu takdirde, özellikle meyve ağaçlarında zarar yapan ambrosya böcekleri için alternatif mücadele yöntemleri geliştirilebilecektir.

\section{Kaynaklar}

Batra, L.R., 1963. Ecology of ambrosia fungi and their dissemination by beetles. Transactions of the Kansas Academy of Science 66: 213-236.

Batra, L.R., 1967. Ambrosia fungi: a taxonomic revision and nutritional studies of some species. Mycologia 59: 976-1017.

Beaver, R.A., 1989. Insect-fungus relationships in the bark and ambrosia beetles. In Insect fungus Interactions, 14th Symposium of the Royal Entomological Society of London, (ed): Wilding, N., Collins, N. M., Hammond, P.M., Webber, J.F., 121 pp.

Beaver, R.A., Liu, L.Y., 2013. A synopsis of the pine-hole borers of Thailand (Coleoptera: Curculionidae: Platypodinae). Zootaxa, 3646: 447- 486 pp.

Biedermann, P.H.W., Taborsky, M., 2011. Larval helpers and age polyethism in ambrosia beetles. Proceedings of the National Academy Sciences of the United States of America 108: 17064 - 17069 pp.

Castrillo, L.A., Griggs, M.H., Ranger, C.M., Reding, M.E., Vandenberg, J.D., 2011. Virulence of commercial strains of Beauveria bassiana and Metarhizium brunneum (Ascomycota: Hypocreales) against adult Xylosandrus germanus (Coleoptera: Curculionidae) and impact on brood. Biological Control 58: 121-126 pp.

Cebeci, H.H., Ayberk, H., 2010. Ambrosia beetles, hosts and distribution in Turkey with a study on the species of Istanbul province. African Journal of Agricultural Research, 5(10): 1055 - 1059 pp.

Douglas, A.E., 2010. The Symbiotic Habit. Princeton University Press, Princeton, New Jersey. ISBN 978-0-691-11341-8, 202 pp.

Farrell, B.D., Sequeira, A.S., O'Meara, B.C., Normark, B.B., Chung, J.H., Jordal, B.H., 2001. The evolution of agriculture in 
beetles (Curculionidae: Scolytinae and Platypodinae). Evolution, 55: 2011-2027 pp.

Francke-Grosmann, H., 1956. Hautdrüsen als träger der pilzsymbiose bei ambrosiakäfern. Zeitschrift für Morphologie und Ökologie der Tiere, 45 (3): 275-308 pp.

Francke-Grosmann, H., 1967. Ectosymbiosis in wood-inhabiting insects. (ed): Henry S.M., Symbiosis. Academic Press, New York, 142-206 pp.

French, J.R., Roeper, R.A., 1972. Observations on Trypodendron rufitarsis (Coleoptera: Scolytidae) and its primary symbiotic fungus, Ambrosiella ferruginea. Annals of the Entomological Society of America, 65: 282-282 pp.

Funk, A., 1970. Fungal symbionts of the ambrosia beetle Gnathotrichus sulcatus. Canadian Journal of Botany, 48 (8): 1445-1448 pp.

Gebhardt, H., Bergerow, D., Oberwinkler, F., 2004. Identification of the ambrosia fungus of Xyleborus monographus and $X$. dryographus (Curculionidae, Scolytinae). Mycological Progress, 3: 95 - 102 pp.

Hain, F., 2006. New threats to forest health require quick and comprehensive research response. Journal of Forestry, 104: 182 $186 \mathrm{pp}$.

Harrington, T.C., 2005. Ecology and evolution of mycophagous bark beetles and their fungal partners. (eds): Vega, F.E., Blackwell, M., Ecological and Evolutionary Advances in Insect-Fungal Associations. Oxford University Press, New York, 257 291 pp.

Harrington, T.C., 2009. The genus Ceratocystis. Where does the oak wilt fungus fit? (eds): Billings, R.F., Appel, D.N., Proceedings of the 2nd National Oak Wilt Symposium Texas Forest Service Publication 166, Austin, Texas, 21 - 35 pp.

Harrington, T.C., McNew, D., Mayers, C., Fraedrich, S.W., Reed, S.E., 2014. Ambrosiella roeperi sp. nov. is the mycangial symbiont of the granulate ambrosia beetle, Xylosandrus crassiusculus. Mycologia, 106: 835 - 845 pp.

Hsiau, P.T.W., Harrington, T.C., 2003. Phylogenetics and Adaptations of Basidiomycetous Fungi Fed upon by Bark Beetles (Coleoptera: Scolytidae). Symbiosis 34: 111 - $131 \mathrm{pp}$.
Hudson, W., Mizell, R., 1999. Management of Asian ambrosia beetle, Xylosandrus crassiusculus, in nurseries. (ed): James, B.L., Proceedings of the 44th Annual Southern Nursery Associated Research Conference, Atlanta, GA. 44: 182 - 185 pp.

Hulcr, J., Adams, A.S., Raffa, K., Hofstetter, R.W., Klepzig, K.D., Currie, C.R., 2010. Presence and diversity of Streptomyces in Dendroctonus and sympatric bark beetle galleries across North America. Microbial Ecology, 61(4): 759 - 768 pp.

Hulcr, J., Cognato, A.I., 2010. Repeated evolution of crop theft in fungus-farming ambrosia beetles. Evolution 64: 3205 - 3212 pp.

Hulcr, J., Dunn, R.R., 2011. The sudden emergence of pathogenicity in insectfungus symbioses threatens naive forest ecosystems. Proceedings of the Royal Society B., 278: 2866 - 2873 pp.

Hulcr, J., Mann, R., Stelinski, L.L., 2011. The scent of a partner: ambrosia beetles are attracted to volatiles from their fungal symbionts. Journal of Chemical Ecology, 37: 1374 - 1377 pp.

Hulcr, J., Mogia, M., Isua, B., Novotny, V., 2007. Host specificity of ambrosia and bark beetles (Col., Curculionidae: Scolytinae and Platypodinae) in a New Guinea rainforest. Ecological Entomology, 32: 762 - $772 \mathrm{pp}$.

Kirisits, T., 2004. Fungal associates of European bark beetles with special emphasis on the ophiostomatoid fungi. (eds): Lieutier, F., Keith, R.D., Battisti, A., Gre'goire, J. C., Evans, H.F., Bark and Wood Boring Insects in Living Trees in Europe, a Synthesis. Springer, Dordrecht, 181 - 237 pp.

Kirkendall, L.R., Biedermann, P.H.W., Jordal, B.H., 2015. Evolution and diversity of bark and ambrosia beetles. (eds): Vega, F.E., Hofstetter, R.W., Bark Beetles: biology and ecology of native and invasive species. Academic Press, 85 - 156 pp.

Kok, L.T., 1979. Lipids of ambrosia fungi in the life of mutualistic beetles. (ed): Batra, L.R., Insect-fungus Symbiosis. Halsted Press, Chichester, Sussex, 33 - 52 pp.

Kok, L.T., Norris, D.M., Chu, H.M., 1970. Sterol metabolism as a basis for mutualistic symbiosis. Nature 225: 661 - 662 pp.

Kostovcik, M., Bateman, C., Klarik, M., Stelinski, L., Jordal, B., Hulcr, J., 2015. The ambrosia symbiosis is specific in some species and promiscuous in others: evidence from 
community pyrosequencing. International Society for Microbial Ecology, 9: 126 - 138 pp.

Kuhnholz, S., Borden, J.H., Uzunovic, A., 2003. Secondary ambrosia beetles in apparently healthy trees: Adaptations, potential causes and suggested research. Integrated Pest Management Reviews, 6: 209 - 219 pp.

Marvaldi, A.E., Sequeira, A.S., O'Brien, C.W., Farrell, B.D., 2002. Molecular and morphological phylogenetics of weevils (Coleoptera, Curculionoidea): do niche shifts accompany diversification? Systematic Biology, 51: 761 - 785 pp.

Mayers, C.G., Mcnew, D.L., Harrington, T.C., Roeper, R.A., Fraedrich, S.W., Biedermann, P.H.W., Castrillo, L.A., Reed, S.E., 2015. Three genera in the Ceratocystidaceae are the respective symbionts of three independent lineages of ambrosia beetles with large, complex mycangia. Fungal Biology, 119: 1075 - 1092 pp.

Mueller, U.G., Gerardo, N.M., Aanen, D.K., Six, D.L., Schultz, T.R., 2005. The evolution of agriculture in insects. Annual Review of Ecology, Evolution and Systematics, 36: 63 - $95 \mathrm{pp}$.

Norris, D.M., 1979. The mutualistic fungi of Xyleborini beetles. See Batra, 53 - 65 pp.

Oliver, J.B., Mannion, C.M., 2001. Ambrosia beetle (Coleoptera: Scolytidae) species attacking chestnut and captured in ethanol-baited traps in middle Tennessee. Environmental Entomology, 30: 909 - 918 pp.

Price, S.L., Murakami, T., Mueller, U.G., Schultz, T.R., Currie, C.R., 2003. Recent findings in fungus-growing ants: Evolution, ecology, and behavior of a complex microbial symbiosis. In Genes, Behavior, and Evolution in Social Insects, (ed): Kikuchi, M., Higashi, S., 255 pp, 80. Sapporo: Hokkaido Univ. Press. 314 pp.

Roeper, R.A., 1995. Patterns of mycetophagy in Michigan ambrosia beetles. Michigan Academician, 26: 153 - 161 pp.

Roeper, R.A., Treeful, L.M., Foote, R.A., Bunce, M.A., 1980. In vitro culture of the ambrosia beetle Xyleborus affinis (Coleoptera: Scolytidae). Great Lakes Entomologist, 13: 33 - 35 pp.

Rollins, F., Jones, K.G., Krokene, P., Solheim, H., Blackwell, M., 2001. Phylogeny of asexual fungi associated with bark and ambrosia beetles. Mycologia, 93: 991 - 996 pp.

Saruhan, I., Tuncer, C., 2001. Population densities and seasonal fluctuations of hazelnut pests in Samsun, Turkey. Acta Hort., 556: 495 - 502 pp.

Saruhan, I., Akyol, H., 2012. Monitoring population density and fluctuations of Anisandrus dispar and Xyleborinus saxesenii (Coleoptera:Scolytinae,Curculion idae) in hazelnut orchards. African Journal of Biotechnology, 11(18): 4202 - 4207 pp.

Schultz, T.R., Meier, R., 1995. A phylogenetic analysis of the fungus-growing ants (Hymenoptera: Formicidae: Attini) based on morphological characters of the larvae. Systematic Entomology, 20: 337 - 370 pp.

Selmi, E., 1998. Türkiye Kabuk Böcekleri ve Savaşı. İstanbul Üniversitesi Yayın No: 4042, Emek Matbaası, İstanbul, $196 \mathrm{pp}$.

Vega, F.E., Blackwell, M., 2005. Insect-Fungal Associations: Ecology and Evolution. Oxford: Oxford Univ. Press, $333 \mathrm{pp}$.

Vega, F.E., Hofstetter, R.W., 2015. Bark beetles: biology and ecology of native and invasive species. San Diego, California: Academic Press, 640 pp.

Wood, S.L., Bright, D.E., 1992. A catalog of Scolytidae and Platypodidae (Coleoptera), Part 2: taxonomic index. Great Basin Nat Mem., 13: 1 - 1553 pp. 